\title{
The ultimate undrained resistance of partially embedded pipelines
}

\author{
R. MERIFIELD*, D. J. WHITE* and M. F. RANDOLPH*
}

\begin{abstract}
On-bottom pipelines for transporting oil and gas in deep water undergo significant changes in temperature and pressure during operating cycles, which cause a tendency for lateral buckling. Prediction and control of this phenomenon are required for the safe design and operation of these pipelines. However, the soil response under combined vertical and lateral loading is a significant area of uncertainty, and current practice relies on empirical expressions for the estimation of lateral pipe-soil resistance. This paper reports the results of finite element (FE) analyses of shallowly embedded pipelines under vertical and horizontal load. These analyses have been compared with collapse loads calculated using the upperbound theorem of plasticity, and are used to construct yield envelopes defining the limiting combinations of vertical and horizontal load. The FE limiting loads were found to compare well with upper-bound plasticity solutions, and the internal soil displacements calculated in the FE analyses match the upper-bound and experimentally observed deformation patterns. The yield envelopes generated by the FE and upper-bound analyses have been fitted by simple solutions, which aid assessment of the ultimate resistance of shallowly embedded pipelines.
\end{abstract}

KEYWORDS: buried structures; clays; failure; numerical modelling and analysis; offshore engineering; plasticity; theoretical analysis
Les conduites de fond transportant du pétrole et du gaz posées sur le fond marin sont soumises à des variations significatives de la température et de la pression au cours des cycles d'exploitation, variations qui déterminent une tendance au flambement latéral. Pour permettre une étude et une utilisation sans danger de ces conduites, il est nécessaire de pouvoir prédire et limiter ce phénomène. Toutefois, la réaction du sol à des charges verticales et latérales est un domaine où règnent de fortes incertitudes, et les méthodes actuelles sont basées sur des expressions empiriques pour l'estimation de la résistance latérale conduite - sol. La présente communication présente les résultats d'analyses aux éléments finis effectuées sur des conduites encastrées en eau peu profonde soumises à des charges verticales et horizontales. On compare ces analyses avec des charges d'affaissement calculées en utilisant le théorème de la limite supérieure de la plasticité, et on les utilise pour former des enveloppes de rendement définissant les combinaisons de limitation des charges verticales et horizontales. On a relevé que les charges de limitation aux éléments finis présentaient de bons résultats lorsqu'on les comparait aux solutions de la limite supérieure de la plasticité, et les déplacements internes du sol dans les éléments finis sont comparables à la limite supérieure et aux tendances de déformation relevées de façon expérimentale. Les enveloppes de rendement produites par les analyses aux éléments finis et de limite supérieure ont été installées par de simples solutions facilitant l'évaluation de la résistance limite de conduites encastrées en eau peu profonde.

\section{INTRODUCTION}

\section{Background and objectives}

As oil and gas developments move into deeper water, the associated pipelines represent an increasingly significant part of the facility costs. Deep-water pipelines are usually laid on the seabed, penetrating by a fraction of a diameter owing to self-weight and the effects of the laying process. The pipelines are laid at ambient temperature, but are required to operate at high temperatures and pressures. The axial stress induced by the change in temperature from the as-laid condition causes a tendency for the hot pipeline to buckle, and break out from the initial partially embedded position. Controlled lateral buckling can represent a cost-effective solution to the problem of thermal loading, but requires reliable assessment of the soil resistance during lateral pipe motion (Bruton et al., 2006). This paper is concerned with the ultimate resistance of a pipeline that is shallowly embedded in soft fine-grained sediment, as is typically found in deep waters offshore.

The purpose of this paper is to present finite element (FE) analyses of a shallowly embedded pipeline under vertical

Manuscript received 23 May 2007; revised manuscript accepted 3 April 2008.

Discussion on this paper closes on 2 February 2009, for further details see p. ii.

* Centre for Offshore Foundation Systems, University of Western Australia. and horizontal load. These analyses are compared with collapse loads calculated using the upper-bound theorem of plasticity, and are used to construct yield envelopes defining the limiting combinations of vertical and horizontal load. The yield envelopes generated by the FE and upper-bound analyses are fitted by simple solutions, which provide a basis for assessing the ultimate resistance of shallowly embedded pipelines, and are suitable for incorporation into forceresultant plasticity models for pipe-soil interaction.

\section{Previous studies}

To ensure that the lateral buckles form as planned, accurate predictions must be made of the initial pipe embedment after laying, and the subsequent response under combined horizontal and vertical loading, imposed by the thermal and self-weight loading respectively. Plasticity solutions for the vertical collapse load of a shallowly embedded pipeline were presented by Murff et al. (1989), and provide the basis for assessing the as-laid embedment of a pipe. In addition to the pipe self-weight, the lay process creates additional vertical load due to the stress concentration where the pipe touches down on the seabed due to the catenary shape. Also, motion of the lay vessel and hydrodynamic loading of the hanging section of pipe will cause additional vertical and horizontal motion at the touchdown point.

The solutions of Murff et al. (1989) were extended by Aubeny et al. (2005) to consider soil profiles with the shear 
strength varying linearly with depth. They found that normalising the penetration resistance by the shear strength at invert level $\left(s_{\mathrm{u}, \text { inv }}\right)$ led to remarkably close grouping of the penetration curves, independent of the precise strength profile. They proposed a curve fit for the penetration resistance given by

$$
\frac{V}{s_{\mathrm{u}, \text { inv }} D}=a\left(\frac{w}{D}\right)^{b}
$$

where $V$ is the vertical load; $D$ is the pipe diameter; $s_{\mathrm{u}, \text { inv }}$ is the soil shear strength at penetration; and $w$, and $a$ and $b$ are fitting coefficients for limiting conditions of roughness. For a perfectly rough pipe Aubeny et al. (2005) suggest $a=$ 7.41 and $b=0.37$. For a perfectly smooth pipe $a=5.42$ and $b=0 \cdot 29$.

To predict the horizontal load $H$ required for the pipe to move laterally, current practice is to use empirical expressions calibrated from model tests (e.g. Brennodden et al., 1989; Wagner et al., 1989; Verley \& Lund, 1995; Bruton et al., 2006). These expressions generally divide the ultimate lateral resistance into two contributions: (a) a 'frictional' component, which is linked to the current vertical load $V$ (which is the pipe weight); and (b) a passive component, linked to the embedment depth of the pipe $w$ and the soil undrained strength $s_{\mathrm{u}}$.

$$
H=\mu V-\lambda s_{\mathrm{u}} w
$$

Recommended values of the 'friction' coefficient $\mu$ and the embedment coefficient $\lambda$ vary with soil type, but are typically in the ranges $0.2<\mu<1$ and $0.5<\lambda<2$. Verley \& Lund (1995) and Bruton et al. (2006) link $\lambda$ to the ratio of soil strength to unit weight. The general form of equation (2) predicts a linear increase in lateral resistance with both embedment depth and pipe weight, matching the general trends observed for the typical light pipelines with normalised weight, $V / s_{\mathrm{u}} D<1.5$, as is typical for single-bore pipelines. However, this behaviour is not found for heavier pipelines on soft soils, such as some pipe-in-pipe systems on normally consolidated clays, for which $V / s_{\mathrm{u}} D$ can exceed 2 . There is a need to establish a sound theoretical basis for predicting ultimate lateral resistance, to eliminate the current reliance on empirical expressions such as equation (2), and to allow safe extrapolation beyond previous experience.

\section{Problem definition}

The problem as considered in the finite element analysis is illustrated in Fig. 1. A pipe of diameter $D$ rests within a layer of weightless clay with undrained shear strength $s_{\mathrm{u}}$ and infinite thickness. The pipe is considered as being infinitely long, so the numerical convenience of plane-strain conditions can be exploited. In this paper solutions have been computed for problems where $w / D$ ranges from $0 \cdot 1$ to $0 \cdot 5$, which is the zone of most interest for typical single-bore pipelines with low normalised weight.

The collapse load for a pre-embedded pipe is evaluated from the load path followed when the pipe is displaced or 'probed' at an angle $\delta$ to the horizontal (Fig. 1). By probing at various values of $\delta$, a yield envelope can be constructed. A positive value of $\delta$ is associated with downward pipe movement, and a negative value of $\delta$ is associated with heave.

\section{Limitations}

To allow generality, this analysis involves some simplifications compared with the actual conditions relevant in practice. The pipeline is 'wished-in-place', with no heaved soil

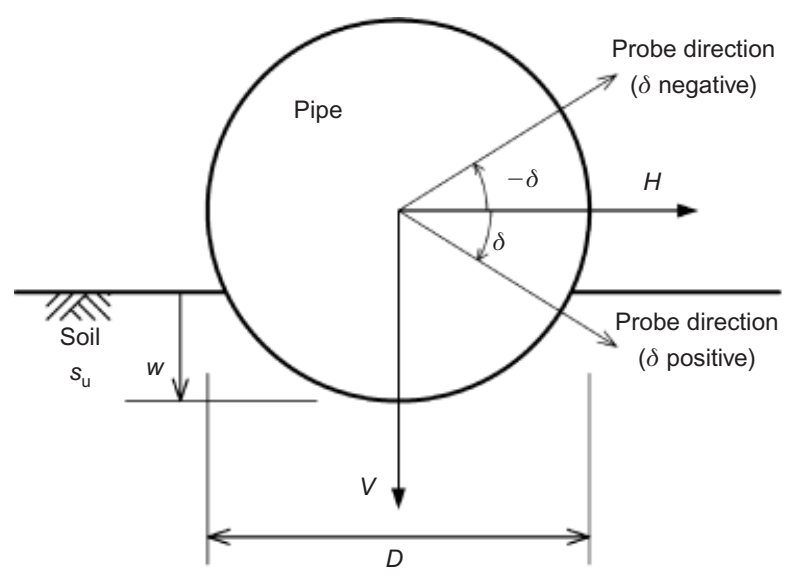

Fig. 1. Problem definition

present around the shoulders of the pipe. Heave would lead to increased lateral resistance, but inclusion of heave would require a much more sophisticated form of analysis, mimicking the full process of pipe embedment.

Also, the soil is assumed to be weightless, although the effect of soil weight is generally small compared with the resistance generated by the strength of the soil and in any case can be accounted for quite simply. The soil strength is uniform, and therefore unaffected by the installation of the pipe, and any subsequent consolidation in the period between embedment and lateral loading. In reality, the installation process will lead to some remoulding and possible loss of strength in the soil around the pipe, which will be countered by consolidation under the weight of the pipe (and any contents) prior to lateral loading.

Finally, it is assumed that the pipe does not rotate as it moves laterally, and the lateral movement is conducted at a rate such that no tension can be sustained between the pipe and the soil at the rear. In practice, the rate of lateral movement will affect the possibility of tension being sustained at the rear of the pipe, and also the operative shear strength within the failing soil.

\section{FINITE ELEMENT ANALYSIS: METHODOLOGY}

The displacement FE software ABAQUS was used for solving this problem. The ABAQUS model consisted of two parts: the pipe and the soil. A typical mesh for this problem, along with the applied displacement boundary conditions, is shown in Fig. 2.

The actual distribution and concentration of elements varied as a function of the pipe embedment depth $w$ and the direction of the applied pipe movement $\delta$. The optimum distribution of elements was obtained using the mesh adaptivity process option available in ABAQUS. The unstructured mesh primarily comprised four-noded quadrilateral plane strain elements, which were found to provide the best solution convergence. The overall mesh dimensions were selected to ensure that the zones of plastic shearing and the observed displacement fields were contained within the model boundaries at all times.

The soil was modelled as an isotropic elasto-perfectly plastic continuum, with failure described by the MohrCoulomb yield criterion. The elastic behaviour was defined by a Poisson's ratio $v=0 \cdot 49$, and a ratio of Young's modulus to shear strength of $E / s_{u}=400$. Because the pipe is much stiffer than the soil it comes into contact with, and as the stresses in the pipe are of no concern in this case, the 


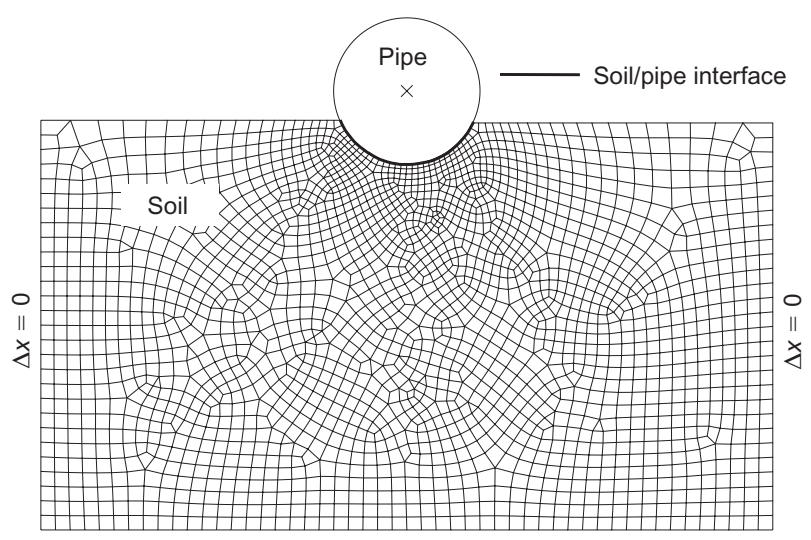

Fixed $(\Delta x=\Delta z=0)$

Fig. 2. Finite element mesh and boundary conditions

pipe was modelled as a discrete rigid body. This simplification provides significant computational savings.

For the problem presented, the pipe/soil interface was modelled using the surface-to-surface small-sliding master/ slave approach as formulated in ABAQUS. The master (pipe) and slave (soil) surfaces were defined as shown in Fig. 2. Only the elements of the pipe and soil domain originally in contact at the beginning of the analysis were defined as interacting surfaces. This eliminated the possibility of material on the soil surface coming into contact with the pipe as the analysis progressed. A small-sliding approach was seen as appropriate, given that geometrically non-linear effects were neglected, and there was no need to maintain clearances between the soil and pipe since large deformation effects such as heave were not being considered.

The strength of the pipe/soil interface was modelled using an interface roughness $\alpha$, where the maximum shear stress at the interface $\tau_{\max }=\alpha s_{\mathrm{u}}$. The 'rough' and 'smooth' extremes of interface strength have been modelled, corresponding to $\alpha=1$ and $\alpha=0$ respectively. A no-tension condition - allowing separation (or 'breakaway') of the pipe from the soil-has been imposed at the pipe/soil interface. Since the soil self-weight is set to zero, separation occurs immediately there is any normal motion of the soil away from the pipe (within numerical tolerances).

Small-strain analyses were performed on the preembedded pipe, therefore neglecting the installation and large-strain aspects of the problem. Such a 'wished-in-place' analysis is of course a simplification of what is actually a very complex problem, as discussed previously. A truly rigorous analysis of this problem would need to include large deformations, large strains, material remoulding and contact conditions that include self-contact behaviour. Nonetheless, as shown by Murff et al. (1989), the wished-in-place approach has proven to provide realistic modelling of vertical pipe embedment, and this paper extends that work to combined vertical-horizontal load.

To determine the collapse load of the pipe, displacementdefined analyses were performed in which the pipe was displaced at an angle $\delta$. A prescribed displacement was applied to the reference node at the centre of the pipe, resulting in uniform motion of the entire pipe. The total displacement was applied over a number of sub-steps, and the total nodal contact forces along the pipe/soil interface in the horizontal $(H)$ and vertical $(V)$ directions were used to calculate the ultimate resultant load $R\left(R=\sqrt{H^{2}+V^{2}}\right)$. By observing the load-displacement response, a check can be made to ensure that the limiting soil resistance has been reached and that overall collapse has occurred.

\section{UPPER-BOUND PLASTICITY SOLUTIONS:} METHODOLOGY

Yield envelopes representing the limiting combinations of vertical and horizontal load to cause geotechnical failure of the pipe were also derived from upper-bound solutions. These were based on a single generic mechanism, which is illustrated in Fig. 3. A detailed description of the upperbound calculations is provided by Randolph \& White (2008), so only a brief overview is included here. The mechanism comprises two parts. In front of the advancing pipe there is a generalised form of the rotational mechanism devised by Martin for the lateral motion of a cylinder through soil (Martin \& Randolph, 2006). The generalisation is that, since the centre (S) of the mechanism does not (in general) lie on a diameter normal to the direction of motion, the angular rotation varies within the rotational mechanism, leading to internal shearing between adjacent cylindrical 'shells' centred on S. The mechanism may be continued through to the soil surface (with point $\mathrm{C}$ then lying on $\mathrm{FE}$ ) or may be replaced by a fan (centred on F) and wedge system, much as in the standard upper bound for a shallow strip footing but with internal shearing determined by the angular velocity distribution within the rotational mechanism.

The second part of the mechanism comprises a rigid rotating 'Martin' mechanism, just as for a cylindrical pile. The centre of rotation is at $\mathrm{Q}$, lying on a diameter normal to the direction of motion and at a distance $\lambda D / 2$ from the pipe centre. Breakaway between the pipe and the soil is considered to occur at the point where the pipe circumference is parallel to the direction of motion.

Under purely vertical motion of the pipeline, the above two mechanisms become mirror images of each other, and in most cases the centres of rotation for each mechanism lie on the horizontal diameter of the pipe. However, at very shallow embedment, the optimum mechanism requires the centres of rotation to lie within the lower half of the pipe (always above a line joining the pipe centre to the junction between pipe and soil), so that the left-hand mechanism takes the generalised form referred to above.

In all the upper-bound calculations it was assumed that the pipe itself did not rotate. In practice it is likely that the torsional rigidity of the pipe would be sufficient to restrain the pipe against rotation. Free rotation of a rough pipe under combined horizontal and vertical loading would lead to a reduction in capacity, with limiting resistance close to that for a smooth pipe.

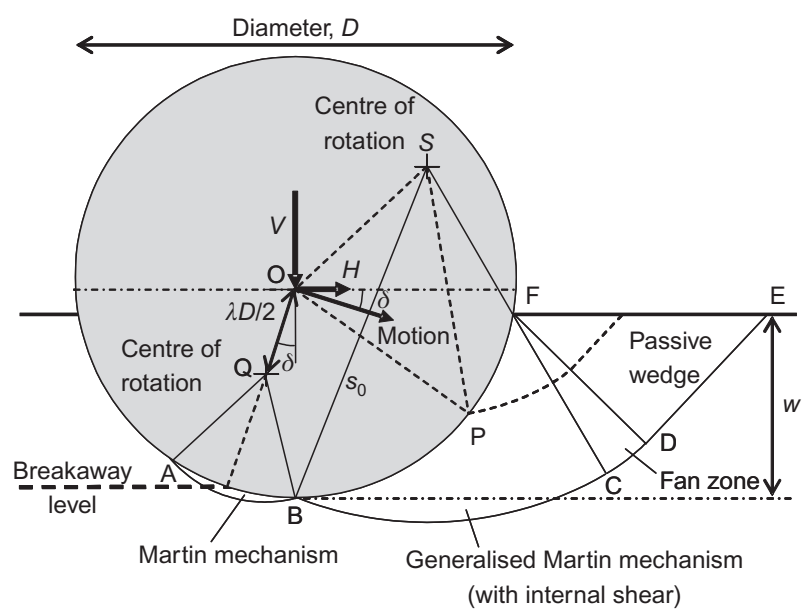

Fig. 3. Definition of upper-bound mechanism 


\section{RESULTS}

Finite element results

Figure 4 shows the ABAQUS FE results for the ultimate load plotted in $V-H$ space for (a) rough and (b) smooth pipes. The collapse load for the pre-embedded pipe was evaluated by displacing the pipe at angles of $\delta$ ranging from $-45^{\circ}$ to $+90^{\circ}$. This range was found to provide a good spread of points along the resulting yield envelope.

The ABAQUS results represent points on the load-displacement response for each embedment depth where the maximum resultant load occurs. The typical resultant load against relative pipe displacement $(\Delta / D)$ response for rough pipes is shown in Fig. 5 for (a) $w / D=0 \cdot 1$ and (b) $w / D=0 \cdot 4$. Also shown in this figure are the points where the maximum resultant load occurs. In general, it was found that the loaddisplacement plot reached a clear plateau within a pipe movement of less than $8 \%$ of the diameter (i.e. $\Delta / D \leqslant 0 \cdot 08$ ).

The maximum resultant load points can be seen for smooth and rough pipes at an embedment of $w / D=0.3$ in the $V-H$ load paths plotted in Fig. 6. Each curve represents the development of horizontal to vertical load capacity as the FE analysis progresses. The ultimate resultant load for each embedment depth is selected as the point furthest away from the yield envelope origin, and is calculated as $\sqrt{H^{2}+V^{2}}$. The ultimate resultant load is illustrated by the arrow shown in Fig. 6(a) for a rough pipe displaced downwards at $\delta=26^{\circ}$ and in Fig. 6(b) for a smooth pipe displaced horizontally $\left(\delta=0^{\circ}\right)$. The final shape of the yield surface is taken as a line of best fit that passes through the points of ultimate resultant load. The best-fit curves are shown as solid lines in Fig. 6.

The manner in which ABAQUS handles frictional slip causes the yield envelopes for a rough pipe to show an 'overshoot' behaviour where the load paths extend outside the final fitted yield surface. This is illustrated in Fig. 6(a) for $w / D=0 \cdot 3$, but was observed for all embedment depths, and deserves further cautionary discussion.

In the penalty formulation of Coulomb friction, ABAQUS approximates the condition of no relative sliding motion with a stiff elastic behaviour. The elastic stick-slip stiffness is by default a function of the contact pressure and a critical value of elastic slip, which dictates when true slip occurs. Using the ABAQUS default settings will lead to a very stiff stick-slip interface response, particularly for highly refined meshes. Consequently, the development of shear stress on the pipe/soil interface, and therefore the development of horizontal and vertical components of load, is very rapid. The interface shear stresses very quickly reach the maximum limiting value of $\tau_{\max }=s_{\mathrm{u}}$, and can overshoot. This is reflected by the steep initial slope of the $V-H$ load paths in Fig. 6.

The absence of overshoot behaviour for smooth pipes (Fig. 6(b)) confirms that this is the origin of the phenomenon. Nonetheless, several analyses were performed where the elastic stick-slip stiffness was reduced by adjusting the ABAQUS default values. This produced identical collapse loads but, importantly, the overshoot behaviour was not observed, and the new load paths were fully contained inside the final fitted yield surface.

\section{Upper-bound results}

Also shown in Fig. 4 are the upper-bound yield envelopes, which are remarkably close to the FE results. For the rough pipe, the largest discrepancy is for purely vertical load for the extreme cases considered, penetrations of $0 \cdot 1 D$ and $0 \cdot 5 D$. For the latter case, the upper-bound capacity under purely vertical load is $V / s_{\mathrm{u}} D=5 \cdot 6$. Although this is

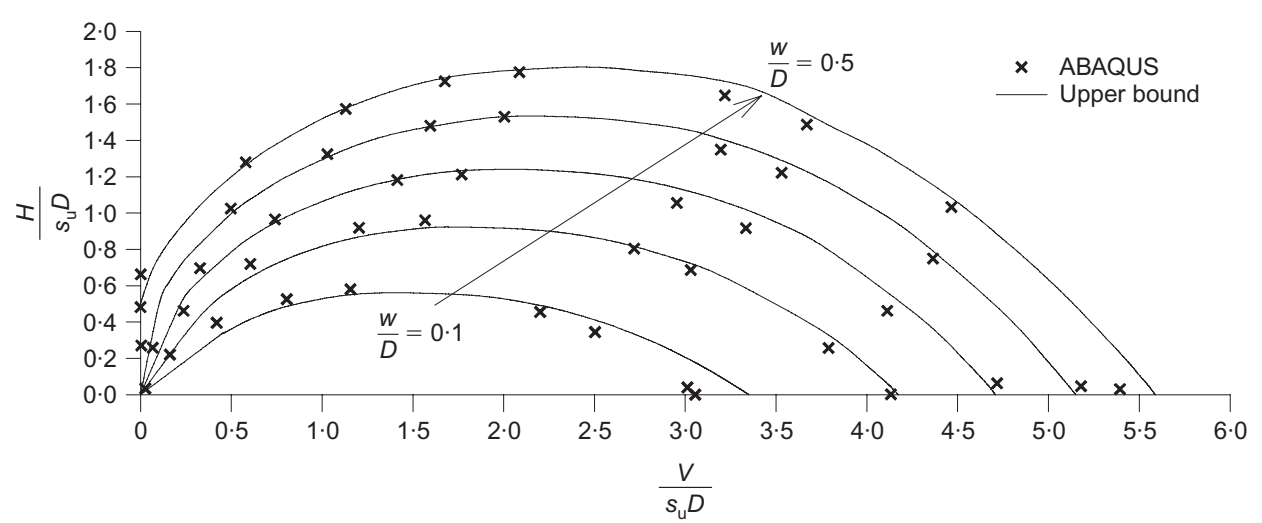

(a)

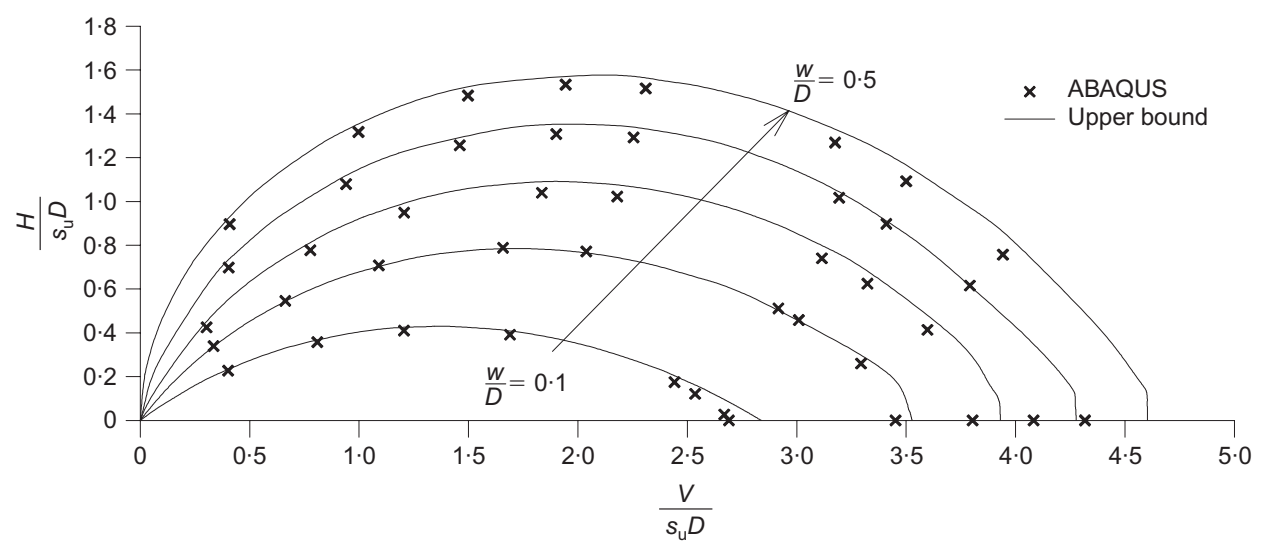

(b)

Fig. 4. Comparison of ABAQUS and upper-bound results: (a) rough pipes; (b) smooth pipes 


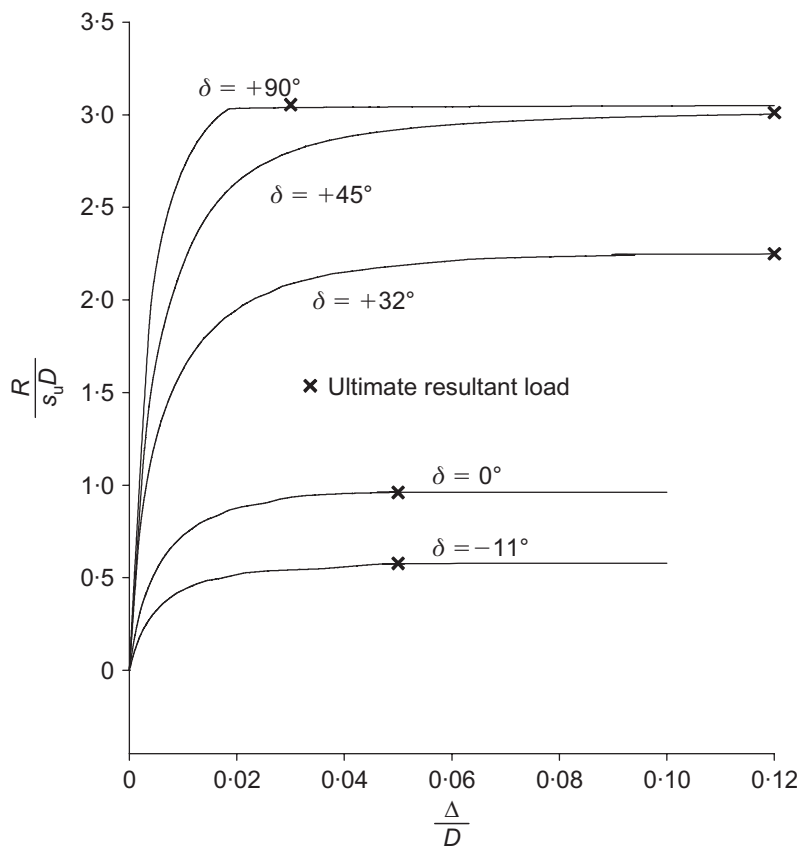

(a)

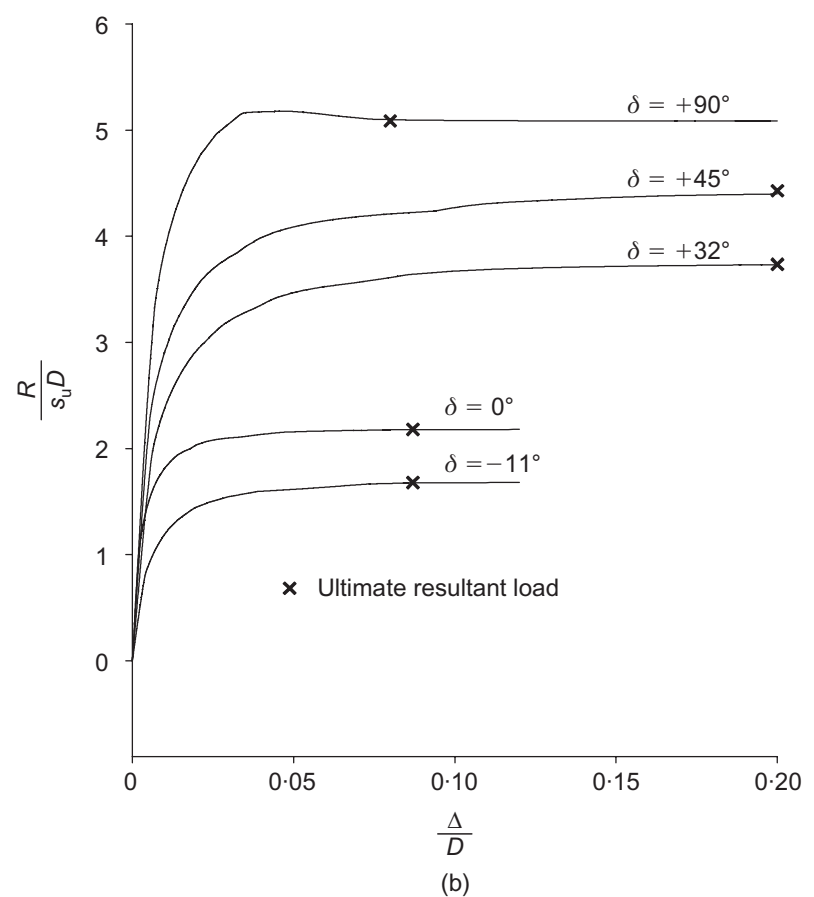

Fig. 5. Load-displacement plots for rough pipes: (a) $w / D=0 \cdot 1$; (b) $w / D=0 \cdot 4$

consistent with the FE results of Aubeny et al. (2005), it is some $3.5 \%$ greater than the current FE limit of $5 \cdot 4$. At the shallowest penetration of $0 \cdot 1 D$, a simple Prandtl mechanism yields an upper bound of $V / s_{\mathrm{u}} D=3 \cdot 09$, and a modified Green's solution (Green, 1954) allows the nose of the upper-bound envelope to be truncated by a line given by

$$
\frac{V}{s_{\mathrm{u}} D} \approx 3.09-1 \cdot 2 \frac{H}{V}
$$

For high $H / V$ ratios, the upper-bound envelopes lie just inside the FE results. For a given embedment $w$ the gradient of the yield envelope at low vertical loads is

$$
\frac{\mathrm{d} H}{\mathrm{~d} V}=\frac{\sqrt{1-(1-2 w / D)^{2}}}{1-2 w / D}
$$

corresponding to a mechanism in which the pipe moves upwards parallel to the circumference at the intersection with the soil surface.

For the smooth pipe, there is also excellent agreement between upper-bound and FE solutions. Again, the largest discrepancy occurs for purely vertical load. At the maximum embedment considered of $w / D=0.5$, the upper-bound capacity is $V / s_{\mathrm{u}} D=4.60$ (exactly half the optimum upper bound for a deeply buried pipe; Martin \& Randolph, 2006), which compares with FE solutions of 4.4 from Aubeny et al. (2005) and 4.3 here. A particular point of interest is that the yield envelopes for a smooth pipe mostly have a blunt nose to them under purely vertical load (the exception being for the shallowest embedment). By contrast, for a rough pipe, the yield envelopes all come to a point, and the optimum upper-bound solutions involve the pipe moving downwards at an angle of between $32^{\circ}$ and $53^{\circ}$. The main reason for this difference is linked to the assumption of breakaway behind the pipe: for a rough condition, asymmetric failure at an angle (with breakaway behind) reduces the plastic work at the pipe/soil interface sufficiently for this to be the optimum mechanism, even for purely vertical load.

\section{Comparison of FE and upper-bound displacement fields}

Several ABAQUS displacement fields and upper-bound velocity fields are shown in Figs 7 and 8 for comparison purposes. Overall, the comparison between FE and upperbound failure mechanisms is excellent, but is not unexpected given the closeness of the predicted yield envelopes from both methods (Fig. 4). The mechanisms are generally similar for rough and smooth pipes for downward pipe movement $(\delta>0)$. However, for upward pipe movement the smooth mechanism extends deeper than for the rough case. The rough mechanism tends to avoid slip at the pipe/soil interface, so a wedge of soil moves ahead of the pipe in the same direction: this behaviour is evident for the case when $w / D=0.2$ and $\delta=-23^{\circ}$.

One interesting observation from the upper-bound failure mechanisms is the existence of a small circular trailing mechanism, as seen in Figs 7 and 8 for rough and smooth pipes with $w / D=0.4$ and $\delta=32^{\circ}$. A trailing mechanism was not observed in the ABAQUS results for this problem. However, the ABAQUS results did reveal a small amount of material flow trailing the pipe for smooth pipes when $\delta=45^{\circ}$. Note that elimination of the trailing mechanism from the upper-bound solution increases the capacity by less than $2 \%$, so it is not an important feature of the collapse.

\section{COMPARISONS WITH PREVIOUS RESEARCH \\ Theoretical results for $V_{\max }$}

The vertical pipe penetration loads from a number of previous studies are compared with the present results in Fig. 9. For the rough pipe case (Fig. 9(a)), the ABAQUS and upper-bound results compare favourably with the results of Murff et al. (1989) and Aubeny et al. (2005), noting that the upper bound for a rough pipe at $w / D=0 \cdot 1$ is reduced to $V / D s_{\mathrm{u}}=3 \cdot 1$ using a Prandtl mechanism.

For smooth pipes (Fig. 9(b)), the ABAQUS and upperbound results compare favourably with the results of Aubeny et al. (2005) for any embedment, but give lower penetration resistance compared with the results of Murff et al. (1989) for $w / D>0 \cdot 1$. This is because the rotational mechanism (Martin \& Randolph, 2006) provides a mechanism for a 


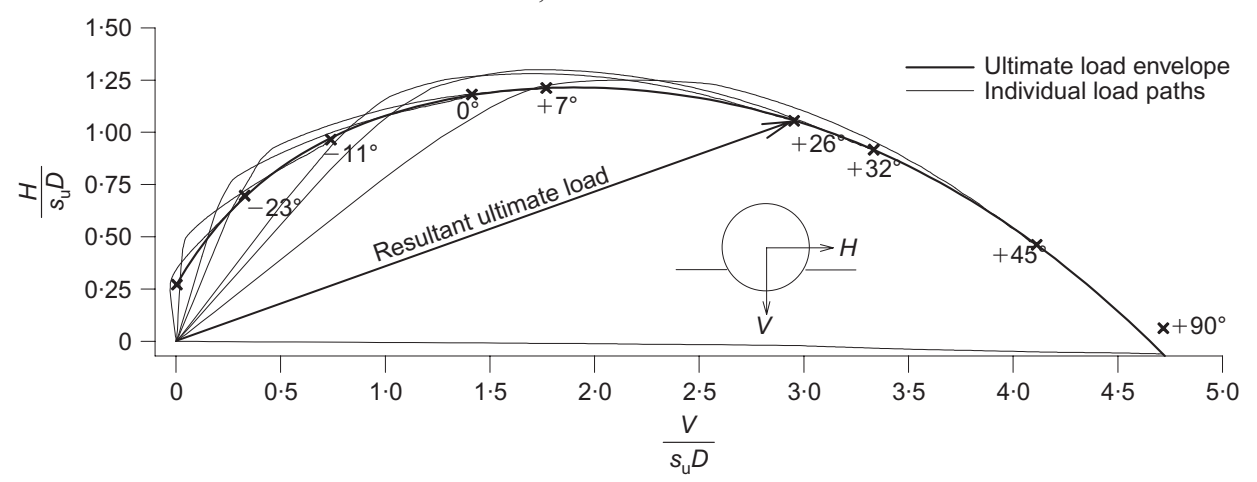

(a)

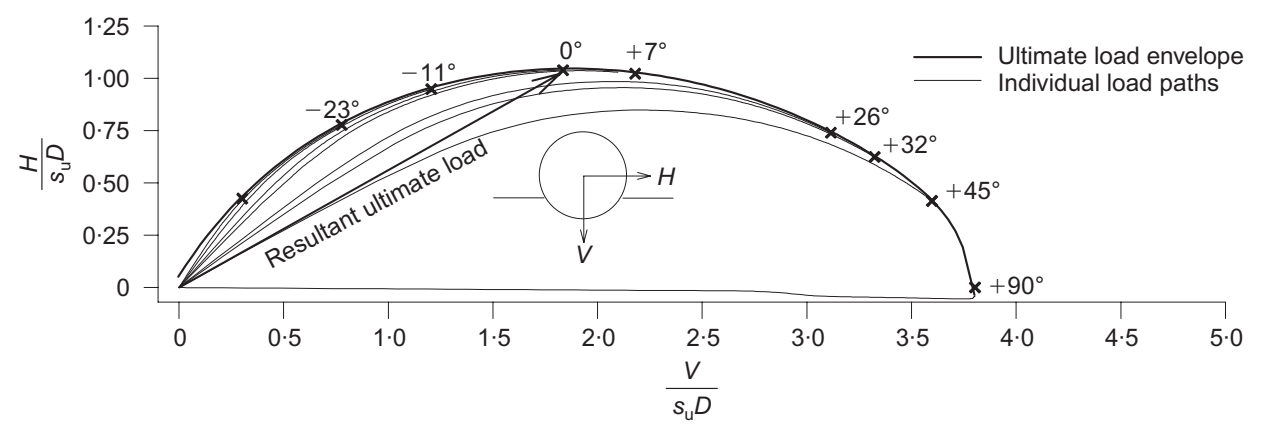

(b)

Fig. 6. Yield envelope for $w / D=0 \cdot 3$ : (a) rough pipe; (b) smooth pipe

smooth pipe/soil interface that is superior to the mechanism used by Murff et al. The difference between the penetration resistance for a rough pipe and that for a smooth pipe rises from about $9 \%$ at an embedment of $0 \cdot 1 D$ to $22 \%$ at an embedment of $0 \cdot 5 D$. The latter figure compares with the difference of $30 \%$ for fully embedded smooth and rough cylinders (Martin \& Randolph, 2006).

\section{Experimental observations of penetration mechanism}

A displacement field from the finite element analysis has also been compared with results from a centrifuge model test of pipe penetration into kaolin clay (Fig. 10). Image analysis has been used to calculate the displacement field during a small increment of penetration of a model pipe into soft clay. These centrifuge tests are described in more detail by Dingle et al. (2008). The model pipe simulated a $0.8 \mathrm{~m}$ diameter pipeline and was penetrated from the soil surface. Images of this process were analysed using particle image velocimetry (PIV) and close-range photogrammetry (White et al., 2003) to obtain a detailed vector field comprising $>9000$ individual points. These results, and the FE nodal displacements for a smooth pipe at an embedment of $w / D=$ $0 \cdot 3$, have been interpolated onto the same grid of points to allow easier comparison.

Figure 10 shows excellent agreement between the experimental and FE vector fields. Both the extent of the mechanisms and the internal velocities are very similar. This shows that despite the idealisations assumed within the FE analysis - in terms of the soil model, and the wished-in-place behaviourthe mechanism of penetration is captured well.

\section{Yield envelopes for surface foundations}

Yield envelopes have been established previously for the response of surface strip foundations under combined load- ing, which are analogous to a pipeline at infinitesimal embedment $(w \rightarrow 0)$. The solution by Green (1954) applies for undrained loading, and is admissible in the case where separation is permitted (i.e. no tension at the foundation/soil interface) (Houlsby \& Puzrin 1999). The maximum value of horizontal capacity given by Green's solution is $H / s_{\mathrm{u}} D=1$ and applies for $V / V_{\max }<0 \cdot 5$. This shape differs from the yield envelopes found in the present analysis, which pass through the load origin $(V=0, H=0)$ for $w / D<0 \cdot 5$, indicating zero lateral resistance in the absence of vertical load.

This contrast shows that for undrained conditions in which separation is permitted, the curved shape of the pipe surface leads to a fundamental difference in the shape of the $V-H$ yield envelope compared with a surface foundation. For a surface foundation under a vertical load less than $V / V_{\max }=$ $0 \cdot 5$, the optimal failure mechanism is always horizontal sliding at the foundation base, and $H / s_{\mathrm{u}} D=1$ (so the slope of the yield envelope, $\mathrm{d} H / \mathrm{d} V=0$ ). In contrast, for a pipe under a comparable vertical load, the failure mechanism involving horizontal translation includes a significant component of resistance due to passive failure of the soil in front of the pipe. This resistance can be reduced by an upwardmoving mechanism, which creates a region of yield surface for which $\mathrm{d} H / \mathrm{d} V>0$ (owing to normality). In the limit, this form of mechanism reduces to upward translation of the pipe, without deformation of the soil, leading to the section of yield envelope given by equation (4).

\section{FITTED EXPRESSIONS FOR PIPELINE YIELD ENVELOPES}

It is useful to fit simple analytical expressions to the yield envelopes and vertical penetration responses generated by the FE and plasticity analyses, to allow these results to be used in routine calculations, and for incorporation into 


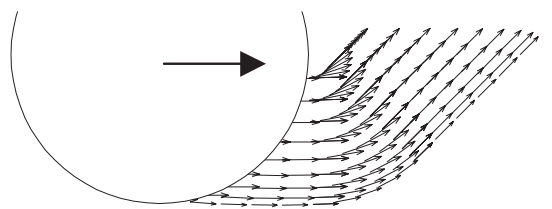

Upper bound

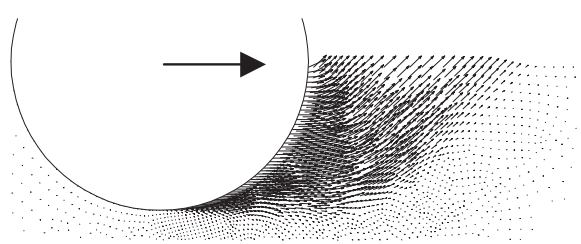

(a)

ABAQUS FE
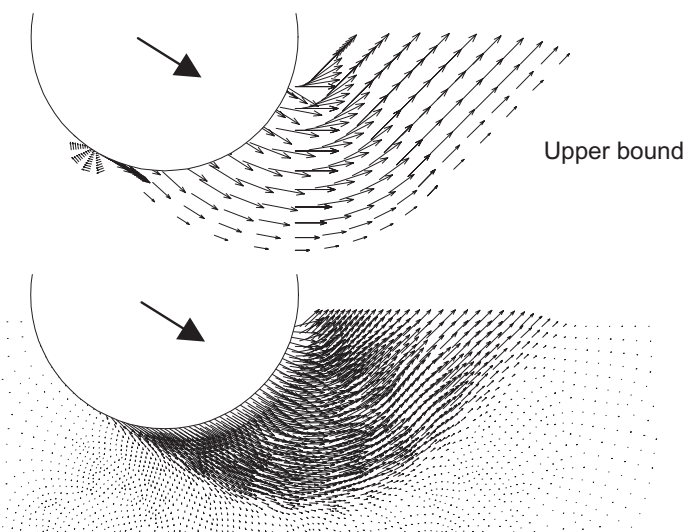

(b)

ABAQUS FE

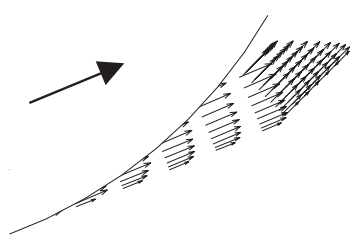

Upper bound

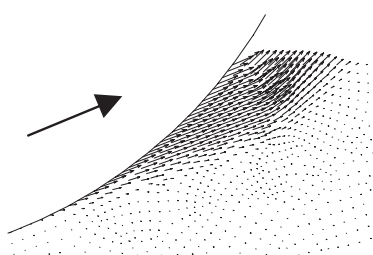

(c)

Fig. 7. FE displacement fields and UB failure mechanisms for rough pipes: (a) $w / D=0.5, \delta=0^{\circ}$; (b) $w / D=0 \cdot 4, \delta=+32^{\circ}$; (c) $w / D=0 \cdot 2, \delta=-23^{\circ}$

force-resultant plasticity models for pipe-soil interaction of the kind described by Schotman \& Stork (1987) and Zhang et al. (2002).

The vertical load-embedment response for rough and smooth pipes is fitted by

Rough:

$$
\frac{V_{\max }}{s_{\mathrm{u}} D}=7 \cdot 4\left(\frac{w}{D}\right)^{0 \cdot 4}
$$
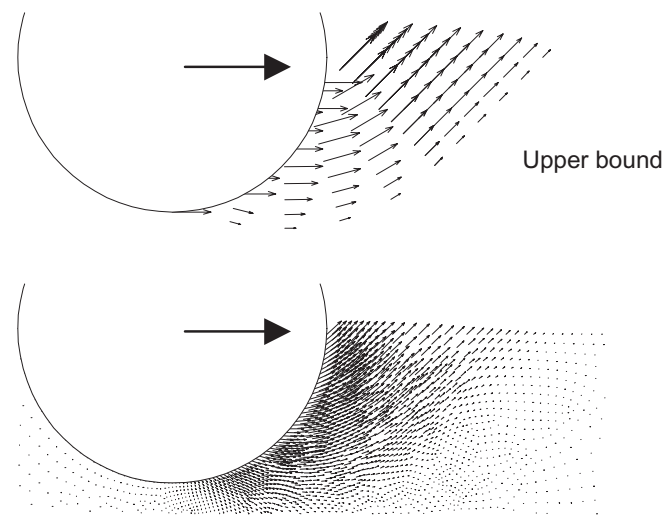

(a)

ABAQUS FE
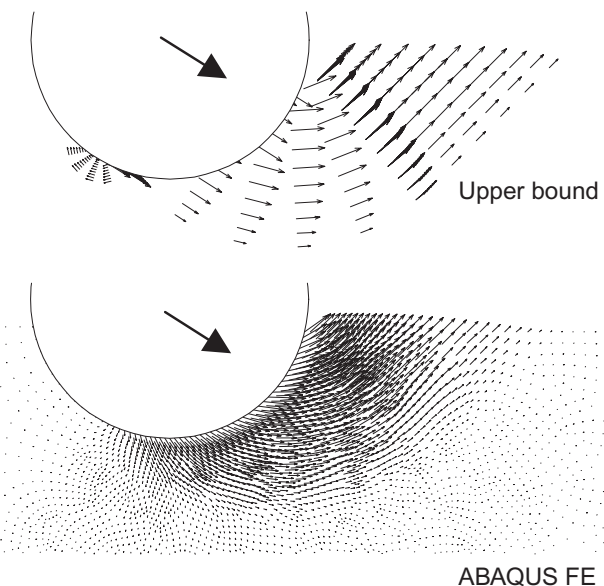

(b)
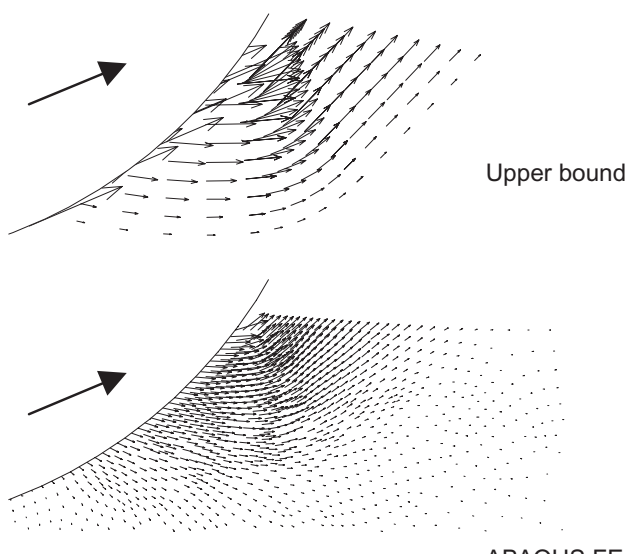

(c)

Fig. 8. FE displacement fields and UB failure mechanisms for smooth pipes: (a) $w / D=0.5, \delta=0^{\circ}$; (b) $w / D=0 \cdot 4, \delta=+32^{\circ}$; (c) $w / D=0 \cdot 2, \delta=-23^{\circ}$

Smooth:

$$
\frac{V_{\max }}{s_{\mathrm{u}} D}=5 \cdot 66\left(\frac{w}{D}\right)^{0.32}
$$

The above equations for vertical penetration are almost identical to those suggested by Aubeny et al. (2005).

For combined loading at a particular embedment, the maximum horizontal resistance $H_{\max }$, normalised by the vertical capacity $V_{\max }$ (which can be assessed from equations 


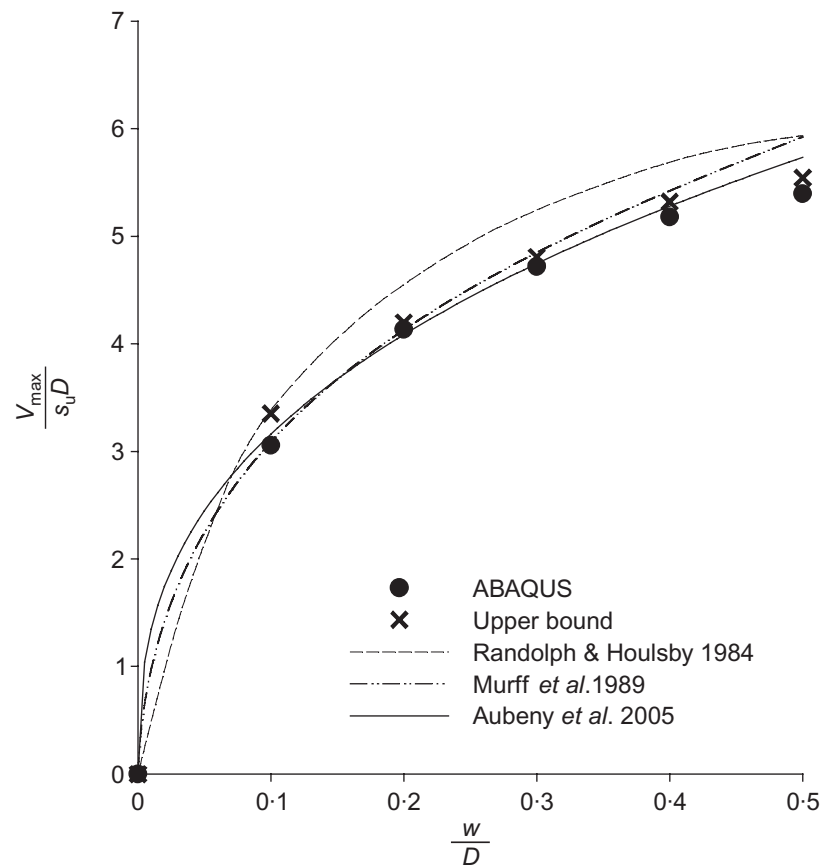

(a)

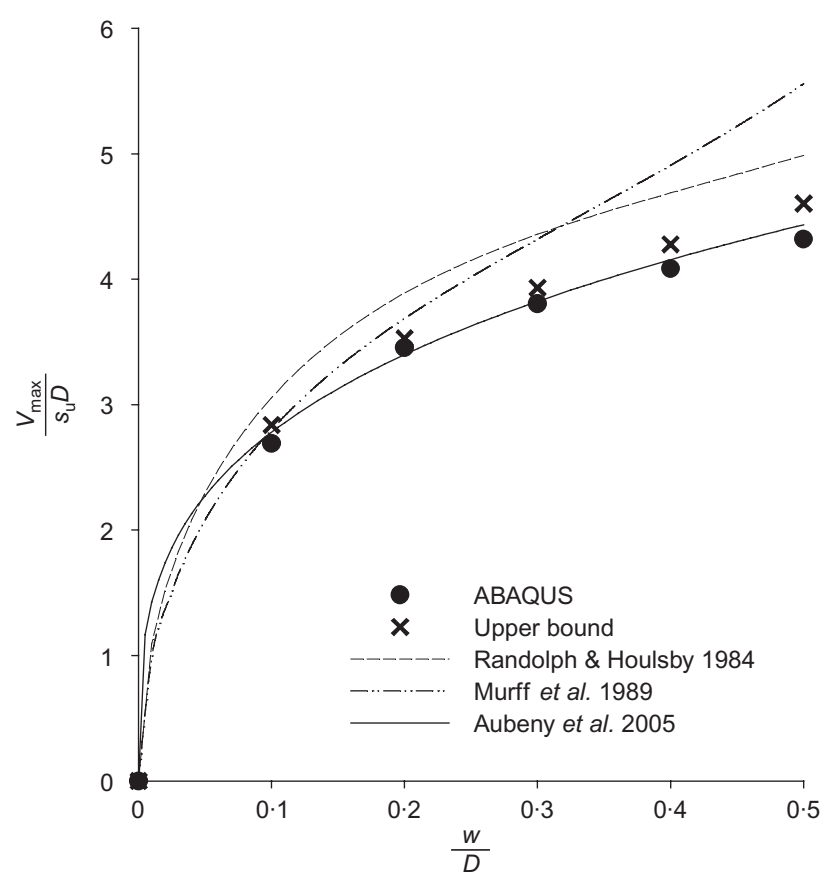

(b)

Fig. 9. Comparison of collapse load for vertical pipe penetration: (a) rough pipes; (b) smooth pipes

(5) and (6)) increases with embedment in a manner that is fitted by:

$$
\frac{H_{\max }}{V_{\max }}=\left(0.48-\frac{\alpha}{25}\right)\left(\frac{w}{D}\right)^{\left(0.46-\frac{\alpha}{25}\right)}
$$

Similar patterns of linearly increasing $H_{\max } / V$ with embedment have been presented by Dean et al. (1993) and Montrasio \& Nova (1997) for surface foundations on sand. In the present analysis the pipe roughness $\alpha$ takes values of 0 and 1 for smooth and rough pipes respectively. A comparison of equation (7) with the FE and upper-bound results is shown in Fig. 11.

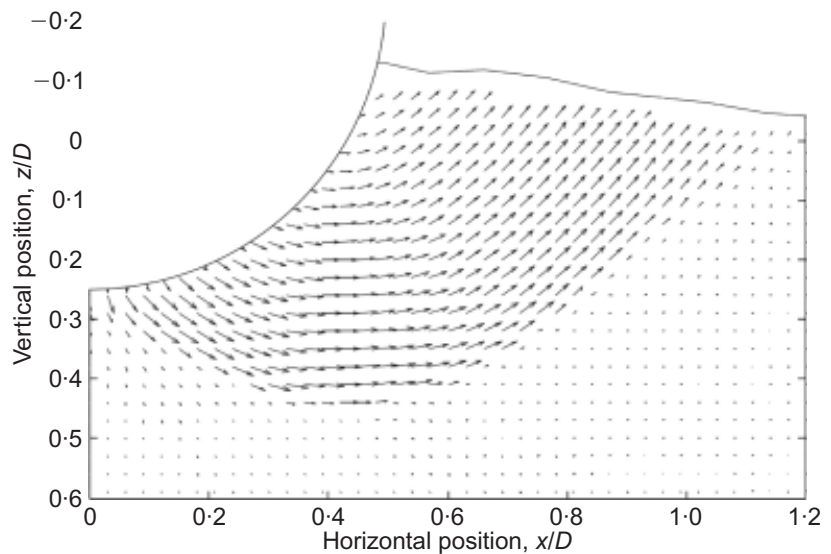

(a)

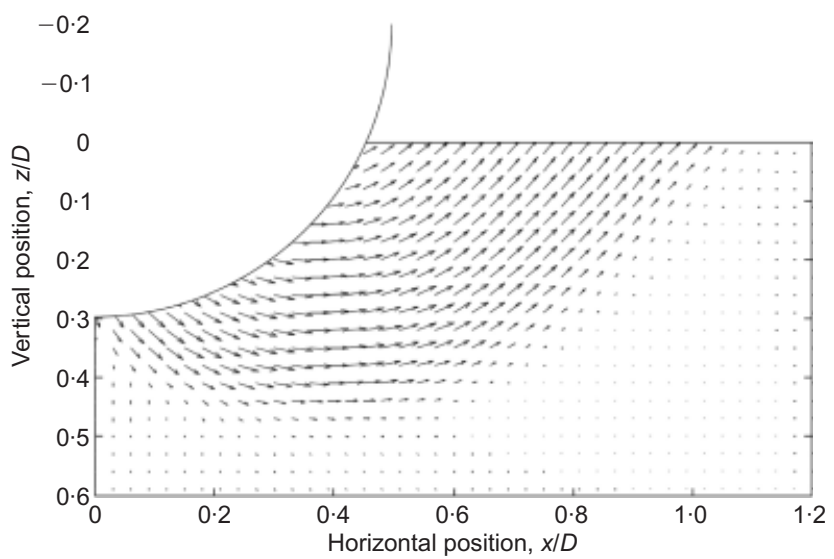

(b)

Fig. 10. Comparison of measured and calculated velocity fields during vertical penetration (for $w / D \approx 0 \cdot 3$ ), smooth pipes: (a) from image analysis of centrifuge model test; (b) from finite element analysis

The general shape of the yield envelopes is parabolic, although the vertical load at which the maximum horizontal resistance occurs changes with embedment, and the envelopes have varying skew. The shapes may be fitted by a generalised parabola incorporating two 'skew' parameters $\beta_{1}$ and $\beta_{2}$, to link the normalised vertical and horizontal failure loads, $h=H / H_{\max }$ and $v=V / V_{\max }$, by

$$
h=\beta v^{\beta_{1}}(1-v)^{\beta_{2}}
$$

where

$$
\beta=\frac{\left(\beta_{1}+\beta_{2}\right)^{\left(\beta_{1}+\beta_{2}\right)}}{\beta_{1} \beta_{1} \beta_{2} \beta_{2}}
$$

These expressions are a two-dimensional simplification of the generalised parabola presented by Martin \& Houlsby (2001) representing a yield envelope for combined loading of spudcan foundations on clay. Nova \& Montrasio (1991) and Georgiadis \& Butterfield (1988) presented similar parabolic envelopes for surface foundations on sand under combined vertical and horizontal loading.

If $\beta_{1}=\beta_{2}=1$, then $\beta=4$ and the expression reduces to a symmetric parabola that lies within the FE and plasticity solutions for any embedment (up to $w / D=0 \cdot 5$ ), so providing an underprediction of ultimate resistance. If $\beta_{1}=\beta_{2}=$ $0 \cdot 4$, then $\beta=1.74$ and the fit lies on the outer limit of the data, and provides an upper estimate. 


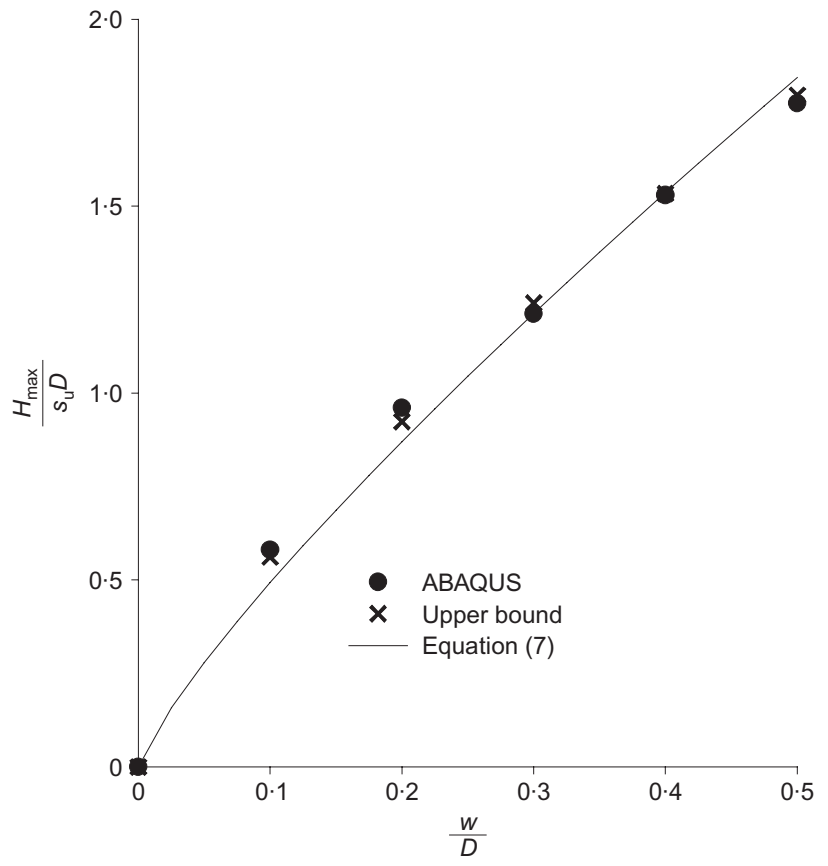

(a)

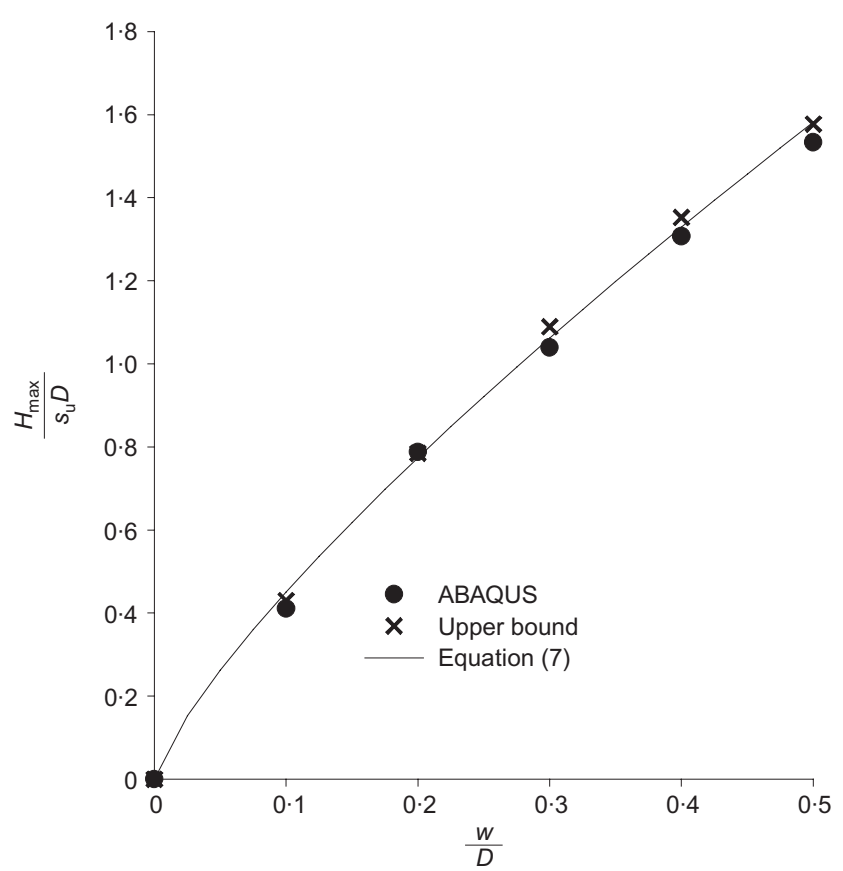

(b)

Fig. 11. Comparison of collapse load for horizontal pipe penetration: (a) rough pipes; (b) smooth pipes

The detailed trend of varying skew with embedment level can be captured by expressing $\beta_{1}$ and $\beta_{2}$ as functions of embedment depth:

$$
\begin{aligned}
& \beta_{1}=(0.8-0.15 \alpha)\left(1.2-\frac{w}{D}\right) \\
& \beta_{2}=0.35\left(2.5-\frac{w}{D}\right)
\end{aligned}
$$

An additional feature of the yield envelopes for rough pipes is the 'frictional' cut-off at low values of $V / V_{\text {max }}$. Within this region the critical failure mechanism involves upward movement of the pipe at a gradient parallel to a tangent to the pipe wall at the soil surface. This mechanism does not involve energy dissipation within the soil, since the entire pipe-soil contact is lost. The work input from the horizontal load simply balances the work done to overcome the vertical load. From the slope of the pipe wall at the soil surface, it can be shown that the cut-off has a 'frictional' form-with the lateral resistance being proportional to the applied vertical load-given by

$$
\frac{H}{V}=\frac{\sqrt{1-[1-(2 w / D)]^{2}}}{1-(2 w / D)}
$$

and extends up to a resultant load of $0 \cdot 5 D s_{\mathrm{u}}$. Equation (12) is the integrated form of equation (4) and lies within the yield envelope given by equation (8) for low values of $V / V_{\text {max: }}$

As the embedment approaches $w / D=0 \cdot 5$, the slope of this cut-off tends to infinity, since the tangent to the pipe wall at the soil surface becomes vertical. For $w / D=0.5$ the envelope has an intercept of $H / s_{\mathrm{u}} D=0.5$ for $V=0$, rather than passing through $V=0, H=0$. However, the values of $\beta_{1}=0.455$ and $\beta_{2}=0.7$ given by equations (10) and (11) provide a very close fit to the numerical results in this region, so it is not necessary to adopt a modified envelope shape to capture this effect. However, some modification would be needed if the analysis were extended to deeper pipe embedment.

The agreement between these fitted expressions and the underlying finite element and upper-bound results is illustrated in Fig. 12. The fitted expressions provide a simple analytical method for calculating the ultimate resistance, or for modelling the generalised behaviour of a partially embedded on-bottom pipeline within a force-resultant plasticity model.

\section{CONCLUSIONS}

Finite element (FE) analysis of a shallowly embedded pipeline has been conducted to provide a more robust basis

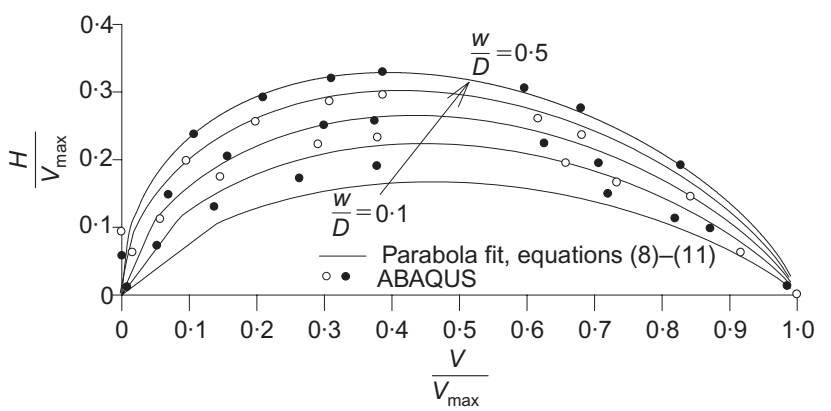

(a)

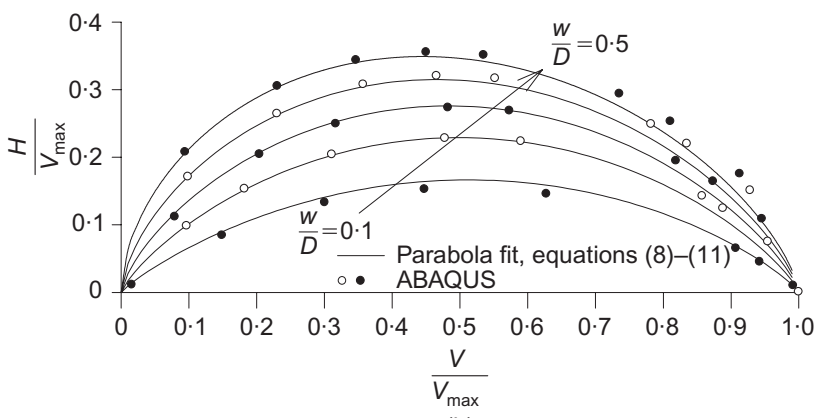

(b)

Fig. 12. Comparison of fitted expressions and calculated results: (a) rough pipes; (b) smooth pipes 
for assessing the ultimate resistance under combined vertical and horizontal loading. Undrained conditions are assumed, and a zero-tension limit is modelled at the pipe/soil interface, allowing separation at the rear of the pipe. The resulting values of ultimate load compare well with upperbound plasticity solutions, and the internal soil displacements calculated in the FE match experimentally observed deformation patterns.

The results have been distilled into simple expressions for combined loading yield envelopes. These envelopes have a 'frictional' cut-off and pass through the load origin, which is a significant difference compared with $V-H$ yield envelopes for surface foundations. This contrast arises from the curved shape of the pipe surface.

The new yield envelopes assist in the assessment of the ultimate resistance of on-bottom pipelines, and capture the underlying behaviour more closely than existing empirical expressions. The envelopes are also suitable for incorporation into force-resultant plasticity models for pipe-soil interaction.

\section{ACKNOWLEDGEMENTS}

This work forms part of the activities of the Centre for Offshore Foundation Systems (COFS), established under the Australian Research Council's Research Centres Program and now supported under grants FF0561473 and DP0665958 and Centre of Excellence funding from the State Government of Western Australia.

\section{NOMENCLATURE}

a curve-fitting coefficient

$b$ curve-fitting coefficient

$D$ pipe diameter

E Young's modulus

$H$ horizontal force per unit length of pipe

$H_{\max }$ maximum horizontal force per unit length of pipe

$h$ normalised horizontal failure load

$R$ resultant load

$s_{\mathrm{u}} \quad$ undrained shear strength of soil

$s_{\mathrm{u}, \text { inv }}$ undrained shear strength of soil at invert of pipe

$v$ normalised vertical failure load

$V$ vertical force per unit length of pipe

$V_{\max }$ maximum vertical force per unit length of pipe

$w$ pipe embedment (measured at invert) below soil surface

$\alpha$ average proportion of mobilised undrained shear strength

$\alpha$ pipe/soil interface roughness coefficient

$\beta_{1}, \beta_{2}$ parabola 'skew' parameters

$\gamma^{\prime}$ submerged unit weight of soil

$\Delta$ pipe displacement

$\delta$ angle of pipe displacement relative to horizontal

$\lambda$ embedment coefficient

$\mu$ friction coefficient

$v$ Poisson's ratio

$\tau_{\max }$ maximum shear stress at the pipe/soil interface, $=\alpha s_{u}$

\section{REFERENCES}

Aubeny, C. P., Shi, H. \& Murff, J. D. (2005). Collapse load for cylinder embedded in trench in cohesive soil. Int. J. Geomech. 5, No. 4, 320-325.

Bruton, D. A. S., White, D. J., Cheuk, C. Y., Bolton, M. D. \& Carr, M. C. (2006). Pipe-soil interaction behaviour during lateral buckling, including large amplitude cyclic displacement tests by the Safebuck JIP. Proc. Offshore Technology Conference, Houston, paper OTC17944.

Brennodden, H., Lieng, J. T., Sotberg, T. \& Verley, R. L. P. (1989) An energy-based pipe-soil interaction model. Proc. Offshore Technology Conference, Houston, paper OTC6057.

Dean, E. T. R., James, R. G., Schofield, A. N., Tan, F. S. C. \& Tsukamoto Y. (1993). The bearing capacity of conical footings on sand in relation to the behaviour of spudcan footings of jackups. Predictive Soil Mechanics: Proc. Wroth Memorial Symposium. Thomas Telford, London, 230-253.

Dingle, H. R. C., White, D. J. \& Gaudin, C. (2008). Mechanisms of pipe embedment and lateral breakout on soft clay. Can. Geotech. J. 45, No. 5, 636-652.

Georgiadis, M. \& Butterfield, R. (1988). Displacements of footings on sand under eccentric and inclined loads. Can. Geotech. J. 25, No. 2, 199-212.

Green, A. P. (1954). The plastic yielding of metal junctions due to combined shear and pressure. J. Mech. Phys. Solids 2, No. 3, 197-211.

Houlsby, G. T. \& Puzrin, A. M. (1999). The bearing capacity of a strip footing on clay under combined loading. Proc. R. Soc. London Ser. A 455, 893-916.

Martin, C. M. \& Houlsby, G. T. (2001). Combined loading of spudcan foundations on clay: numerical modelling. Géotechnique 51, No. 8, 687-699.

Martin, C. M. \& Randolph, M. F. (2006). Upper bound analysis of lateral pile capacity in cohesive soil. Géotechnique 56, No. 2, $141-145$.

Montrasio, L. \& Nova, R. (1997). Settlements of shallow foundations on sand: geometrical effects. Géotechnique 47, No. 1, 49-60.

Murff, J. D., Wagner, D. A., \& Randolph, M. F. (1989). Pipe penetration in cohesive soil. Géotechnique 39, No. 2, 213-229.

Nova, R. \& Montrasio, L. (1991). Settlements of shallow foundations on sand. Géotechnique 41, No. 2, 243-256.

Randolph, M. F. \& White, D. J. (2008). Upper bound yield envelopes for pipelines at shallow embedment in clay. Géotechnique 58, No. 4, 297-301.

Schotman, G. J. M. \& Stork, F. G. (1987). Pipe-soil interaction: a model for laterally loaded pipelines in clay. Proc. Offshore Technology Conference, Houston, paper OTC5588.

Verley, R. \& Lund, K. M. (1995). A soil resistance model for pipelines placed on clay soils. Proceedings of the international conference on offshore mechanics and arctic engineering, Copenhagen, Vol. 5, pp. 225-232.

Wagner, D. A., Murff, J. D., Brennodden, H., \& Sveggenm O. (1989). Pipe-soil interaction model. J. Waterway, Port, Coastal Ocean Engng ASCE 115, No. 2, 205-220.

White, D. J., Take, W. A. \& Bolton, M. D. (2003). Soil deformation measurement using particle image velocimetry (PIV) and photogrammetry. Géotechnique 53, No. 7, 619-631.

Zhang, J., Stewart, D. P., Randolph, M. F. (2002). Modelling of shallowly embedded offshore pipelines in calcareous sand. J. Geotech. Geoenviron. Engng ASCE 128, No. 5, 363-371. 